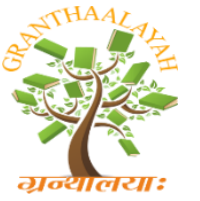

INTERNATIONAL JOURNAL OF RESEARCH GRANTHAALAYAH A knowledge Repository

RAST - 17

\title{
EFFECT OF SOLAR DEHYDRATION METHOD ON PHYSICO- CHEMICAL AND SENSORY CHARACTERISTICS OF GREEN BEANS (PHASEOLUS VULGARIS)
}

\author{
Kuna Priyanka ${ }^{1}$, R.C. Chandni ${ }^{2}$, Amar Sankar ${ }^{3}$, A.V. Raghu ${ }^{4}$ \\ 1, 2, 3,4 Department of Food Technology, Centre for Emerging Technology, Jain University, 562 \\ 112 , India
}

DOI: https://doi.org/10.29121/granthaalayah.v5.i4RAST.2017.3300

\begin{abstract}
Studies were done by different chemical treatments under solar dehydration of Green beans. The Green beans were treated by five different methods which are mentioned and the end product was underwent analysis for physico-chemical characteristics, nutritional characteristics, microbial analysis and sensory evaluation. Five treatments of different proportions with Magnesium chloride, Sodium chloride, Sodium bicarbonate and Magnesium oxide were done for solar dehydration of Green beans and (0.1\% Magnesium chloride and $0.1 \%$ Sodium bicarbonate) treated Green beans were found to be good in all characteristics i.e. Physico-chemical (better chlorophyll retention) and nutritional characteristics when compared to other treatments.
\end{abstract}

Keywords: Green Beans; Chemical Treatments; Solar Dehydration; Physico-Chemical Analysis; Sensory Analysis.

Cite This Article: Kuna Priyanka, R.C. Chandni, Amar Sankar, and A.V. Raghu. (2017). "EFFECT OF SOLAR DEHYDRATION METHOD ON PHYSICO-CHEMICAL AND SENSORY CHARACTERISTICS OF GREEN BEANS (PHASEOLUS VULGARIS)." International Journal of Research - Granthaalayah, 5(4) RAST, 39-44. https://doi.org/10.29121/granthaalayah.v5.i4RAST.2017.3300.

\section{Introduction}

In basic terms, a vegetable is an edible plant and its part intended for cooking purpose or eating raw as it. Some vegetables can be consumed raw, while some such as cassava must be cooked to destroy certain natural toxins or microbes in order to consume. Processed food items available in market contains vegetable ingredients, it can be referred as "vegetable derived" products. These products may or may not maintain nutritional integrity of the vegetables. Thus different vegetable derived products are produced in recent times to maintain nutritional values of vegetables and the nutritional content of vegetables vary from produce to produce. Generally they contain small amount fat, protein and also contain different types vitamins like vitamin A, vitamin $\mathrm{K}$ and vitamin B6, carbohydrates and minerals. Vegetables contain a large variety of 
[Raghu et. al., Vol.5 (Iss.4: RAST), April, 2017]

ICV (Index Copernicus Value) 2015: 71.21

Recent Advances in Science \& Technology
ISSN- 2350-0530(O), ISSN- 2394-3629(P)

IF: 4.321 (CosmosImpactFactor), 2.532 (I2OR)

InfoBase Index IBI Factor 3.86

phytochemicals and some of them have antifungal, antibacterial, antioxidant and anticarcinogenic properties. Few vegetables contain dietary fiber which promotes gastro-intestinal function. In case of drying of green leafy vegetables and vegetables, color loss is the major problem. In blanching process this loss happens more than in unblanched beans. In concern to reduce the chlorophyll loss and other compounds different chemical treatments are done. In either case, vegetables also contain anti-nutrients and toxins which interfere with the absorption of nutrients, those can be inactivated by adequate boiling, drying, soaking etc. Anti-nutrients includes oxalic acid, $\alpha$-solanine, $\alpha$-chaconine enzyme inhibitors and cyanide precursors, cyanide, and others. These toxins are natural defenses, used to ward off the insects and fungi that might attack the plant. Some beans contain vicins and cassava roots contain cyanogenic glycoside. Hygiene is very important while handling because food to be eaten raw foods and such products need to clean properly, handled and stored to reduce spoilage. Green potatoes contain glycoalkaloids and should be avoided. In India, RDI for adults is 275 grams of vegetables per day.

\subsection{Health Benefits}

Green beans have low calories i.e $32 \mathrm{cal} / 100 \mathrm{~g}$ and contain no saturated fats. These pod vegetables are richest sources of vitamins, minerals and phytochemicals. Rich source of vitamin A and polyphenoilc compounds such as $\beta$-carotenes, leutins and zeaxanthins where these compounds possess neutralizing free radical properties and gives immune system and protects against infectious matter and reactive oxygen species that play a role in anti-aging process.

Dietary fiber, $9 \% / 100 \mathrm{~g}$ as per RDA, excellent quantity is present in beans, acts as a bulk laxative which protects the mucus membrane layer of colon by reducing its expose to toxic substances. Binds itself to cancer causers in colon, consequently reducing the risk of cancer. Dietary fiber is also reduces cholesterol levels in blood by reducing re-absorption of cholesterol binding acids in colon. Green beans also contain carotenoid called "Zeaxanthin" which is the compound will be absorbed into eye's retinal macosa and has antioxidant and light filtering property. It also helps in prevention of age related retinal macular diseases. Green beans contain good amounts of folic acid which plays a role in preconception during pregnancy that helps in prevention of neural tube defect in new borns. Potassium is the most important compound for body and cell wall fluid integrity maintenance which control blood pressure and heart rate. The iron element which is available in beans helps in respiration of cell level by producing haemoglobin that carries oxygen molecules to cells and tissues. Molybdenum is the micro mineral that detoxifies sulfites from blood streams. Copper found in better proportions beans, there to lower the chance of inflammatory disease, such as arthritis, maintain the elastic property of vessels, tendons, joints and ligaments by enhancing enzyme activity. Magnesium relieves fatigueness, relaxing of sore muscles, thereby reduces asthma and migraine symptoms. Other than dietary fiber, soluble fiber slow down the carbohydrate metabolism which indirectly regulates blood glucose levels and prevents sudden peaks in blood glucose. It is recommended for diabetic patients for insulin resistant. Folic acid in beans retards the accumulation intermediary metabolite compounds of protein metabolism called "haemocysteine" which promotes the risk of antherosclerosis.

\subsection{Storage}

Care should be taken for post-harvest storage purpose. Sound storage room with better hygiene conditions should be maintained. Tuber and vegetables should be stored by cold chains and 
[Raghu et. al., Vol.5 (Iss.4: RAST), April, 2017]

ICV (Index Copernicus Value) 2015: 71.21

Recent Advances in Science \& Technology
ISSN- 2350-0530(O), ISSN- 2394-3629(P)

IF: 4.321 (CosmosImpactFactor), 2.532 (I2OR)

InfoBase Index IBI Factor 3.86

cellars and method of storing in refrigerated conditions in order to prevent fungal growth and sprouting. As the inherent properties differs from vegetable to vegetable and fruit and fruit care must be taken in understanding the properties of foods to be stored. Maintaining nutritional quality is most important thing in storage of foods. While storing the leafy vegetables as it loose its moisture and vitamin $\mathrm{C}$ has degrades rapidly. It should be stored in a cool place as short a time as possible where it should be packed in a sealed container, tight polyethylene covers or a plastic bag.

\subsection{Nutritive Values of Green Beans}

\begin{tabular}{|l|l|}
\hline Nutrients & Values $\mathbf{( 1 0 0 g )}$ \\
\hline Protein & $2.50-2.70 \mathrm{~g}$ \\
\hline Fat & $0.26-0.28 \mathrm{~g}$ \\
\hline Carbohydrates & $2.68-3.16 \mathrm{~g}$ \\
\hline Fiber & $4.38-4.71 \%$ \\
\hline Thiamine & $0.45 \mathrm{mg}$ \\
\hline Riboflavin & $0.064 \mathrm{mg}$ \\
\hline Niacin & $0.86 \mathrm{mg}$ \\
\hline Pantothenic acid & $0.29 \mathrm{mg}$ \\
\hline Pyridoxine & $0.37-0.423 \mathrm{mg}$ \\
\hline Biotin & $4.71-4.96 \mathrm{mg}$ \\
\hline Folates & $47.45-56.43 \mathrm{mg}$ \\
\hline Vitamin-C & $15.81-20.04 \mathrm{mg}$ \\
\hline$\beta$-carotene & $413-424 \mathrm{IU}$ \\
\hline Calcium & $60 \mathrm{mg}$ \\
\hline Iron & $1.56 \mathrm{mg}$ \\
\hline Phosphorus & $559 \mathrm{mg}$ \\
\hline Energy & $102-110 \mathrm{k.cal}$ \\
\hline
\end{tabular}

(Indian Food Composition Tables, National Institute of Nutrition, 2017)

\subsection{Review}

Blanching is a cooking process usually a vegetable or fruit is plunged into boiling water, removed after a brief time interval and finally dipped in ice water or cold water that give has thermal shock property. Blanching has effect on chlorophyll retention, where chlorophyll converts into pheophytins and oxidates at $-10^{\circ} \mathrm{C}$, it was observed. Chlorophyll can't be retained in steam or water blanching methods. Effects of blanching are enzymes (peroxides and catalases) can be inactivated, reduces microbial load, initial dirt on surface and excludes air spaces in tissues. Dehydration is done under controlled conditions of temperature, humidity \& airflow. The costs of processing are usually high. Air is used as drying medium. Temperature, moisture \& velocity of air are controllable depending on the foods to be dried. Cooking quality foods are superior. Sanitary conditions are controllable with in a dehydration plant. It is a continuous fast process \& the product is obtained within a short period. Dehydration of foods can be carried in all seasons for prolonged shelf life.

\section{Methodology}

\subsection{Production and Processing of Green Beans}

We collected raw green beans from local super market. Green beans which arefree from contaminants are selected for dehydration and procured from the local super markets. The beans were washed under running tap water in order to remove the dust or dirt particles or any 
adhering substances. The washing step increases the quality of final product and decreases the microbial load.Washed beans was made into cuts of 1-1.5 cms, where obtained pieces was subjected to water and steam blanching.Blanching is a heat treatment follows immediate cooling .It helps in fixing the colmy of fruit, removes the air from tissues, inactivates the enzymes. The beans were blanched in boiling water for 2-3 mins. After blanching the surface moisture was removed by blowing hot air for 2-3 min.

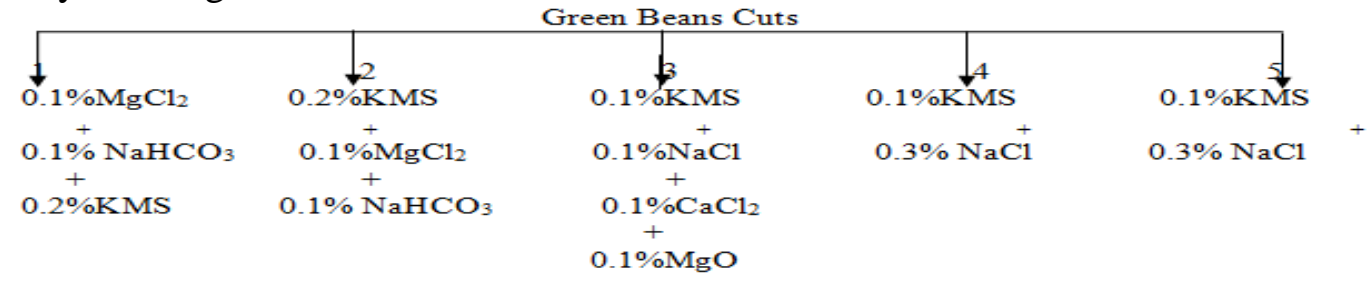

Figure 1: Chemical treatments

In above mentioned 5 treatments: treatments 1 and 5 blanching were not done. Treatment 2 and 3 were water blanching and treatment 4 was steam blanching. Cut beans were placed in tray on the top row of the drying chamber. In such a way the continuity of the drying process could assure without interruption. The drying temperature was shown by thermometer. The maximum temperature in the dryer is $48-54^{\circ} \mathrm{C}$. The time taken for dehydration was $8 \mathrm{hrs}$. Solar dehydration process is attained by placing blue glass filter over the glass cover of dryer. Dehydrated beans are packed in air tight polythene pouches and stored at ambient temperature.

\subsection{Physico-Chemical and Sensory Analysis}

Parameters such as moisture, crude fiber, $\mathrm{pH}$, bulk density were analysed by standard methods. Total chlorophyll, carotenoids, total phenols, flavonoids, vit $\mathrm{C}$, blemish count, rehydration test were carried out according to reported methods suggested by Ranganna (1986). Sensory attributes like appearance, color, taste, flavor, texture and over all acceptability was evaluated by trained panels of 3 judges on nine point hedonic scale. The evaluation was conducted for green beans after rehydration.

\section{Results and Discussion}

\subsection{Processing of Green Beans}

Unit operations involved in the processing of treatment 5 treated green beans is presented in

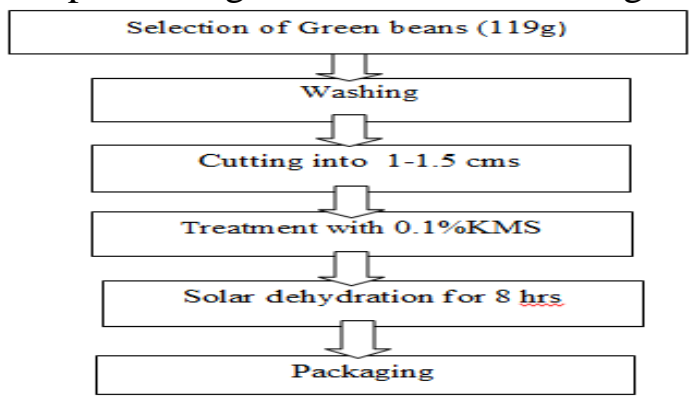

Figure 2: Flowchart of processing Green beans

Studies were done by different chemical treatments under solar dehydration of Green beans. The Green beans were treated by five methods which are mentioned and the end product was 
[Raghu et. al., Vol.5 (Iss.4: RAST), April, 2017]

ICV (Index Copernicus Value) 2015: 71.21

Recent Advances in Science \& Technology
ISSN- 2350-0530(O), ISSN- 2394-3629(P)

IF: 4.321 (CosmosImpactFactor), 2.532 (I2OR)

InfoBase Index IBI Factor 3.86

underwent analysis for physico-chemical analysis and sensory evaluation which are procured from local market. Five treatments of different proportions with Magnesium chloride, Sodium chloride, Sodium bicarbonate and Magnesium oxide were done for solar dehydration of Green beans. From the five chemical treatments; treatment 1 and treatment 5 has been found better in physical characteristics, so those samples are analyzed further. The drying data was observed along with drying hours and \% yield with moisture content under solar dehydration was observed.

\section{Drying table:}

Table 1: Drying data table

\begin{tabular}{|l|l|l|l|l|l|}
\hline Treatment & Initial Wt. (g) & Final Wt. (g) & Yield\% & Drying hours & Cabinet $\left({ }^{\circ} \mathbf{C}\right)$ \\
\hline Control & 200 & 45 & 22.5 & 8 & 60 \\
\hline Treatment 1 & 135 & 26 & 19.25 & 8 & 60 \\
\hline Treatment 2 & 132 & 23 & 17.42 & 8 & 60 \\
\hline Treatment 3 & 152 & 38 & 25 & 8 & 60 \\
\hline Treatment 4 & 122 & 15 & 12 & 8 & 60 \\
\hline Treatment 5 & 119 & 12 & 10 & 8 & 60 \\
\hline
\end{tabular}

\subsection{Physico-Chemical Tests}

Table 2: Physico-chemical analysis

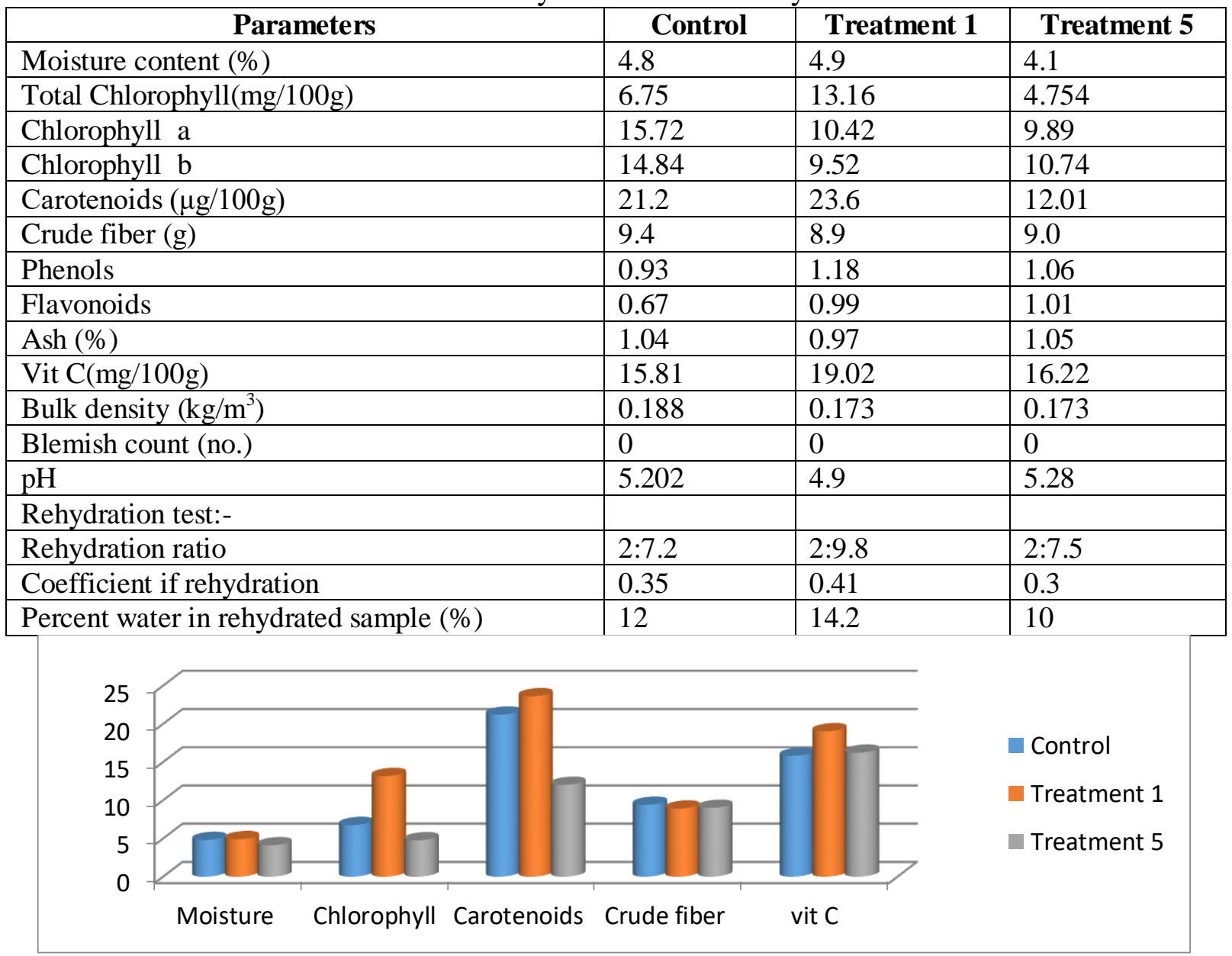


Graph 1: Physico-chemical analysis data

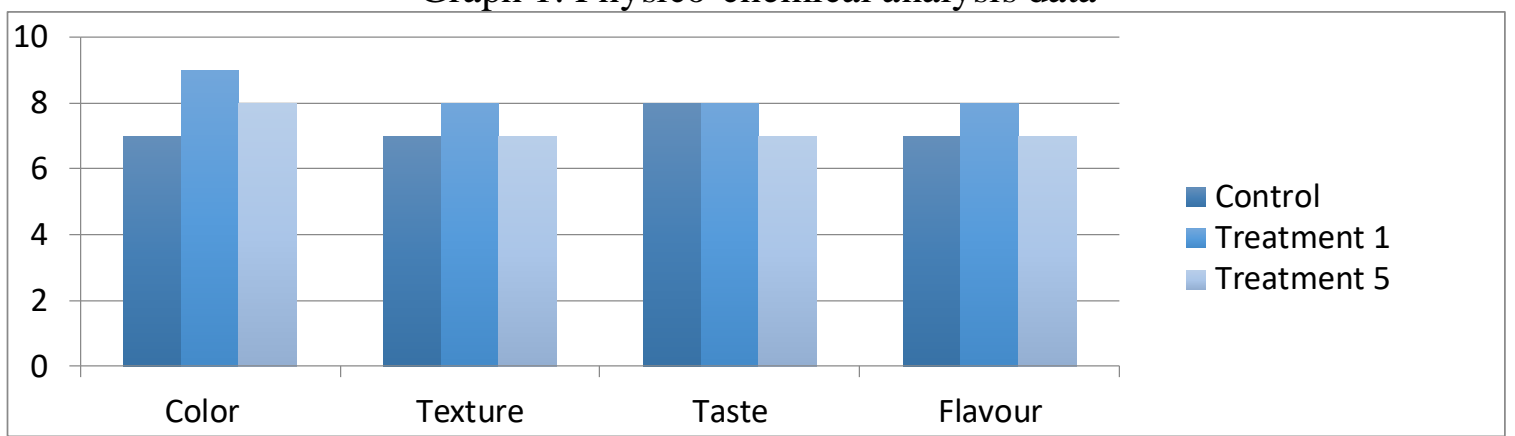

Graph 2: Sensory analysis data

\section{Conclusion}

By referring previous research paper have been concluded that loss of micronutrients, polyphenols and other compounds was very low in solar dehydration with comparison to solar drying. Blanched sample had more loss of chlorophyll even on drying. Not only other compounds; chlorophyll retention is also appreciable as solar dehydrated (blue filter) sample has $13.16 \mathrm{mg}$ where solar dried has 2.69 i.e $\mathrm{MgCl}_{2}$ treated sample retend more than $\mathrm{MgO}$ treated sample. Treatment 1 samples had better points in overall acceptability; it had better color, shape and texture. Rehydration test values have shown better result. Hence, it's concluded that treatment 1 sample show better characteristics in all aspects.

\section{Acknowledgements}

We thank the Ministry of Food Processing and Industries, (MOFPI), Government of India for the award of Food Technology Centre, CET, Jain University.

\section{References}

[1] Subhash B. Kakade and Neeha V.S ,2014 "Dehydration of Green Leafy Vegetable: Review",

[2] G.D Pati, I.L,Pardesh and K.J. Shinde "Drying of Green Leafy Vegetables Using Microwave Oven Dryer “

[3] Papu Singh et al., 2015 "The Drying Characteristics Of Amaranth Leaves Under Greenhouse Type Solar Dryer and Open Sun"

[4] Seidu J.M., et al., 2008 "Preservation of Indigenous Vegetables By Solar Drying"

[5] Adolfo G. Finck-Pastrana 2014 "Nopal Drying Using an Indirect Solar Dryer"

[6] M.Shafiur Rahman "Food Preservation " Second Edition

[7] G.C. walker, 2006 " Color Deterioration in Frozen French Beans"

[8] Reynoso-Camacho et al., 2006 "Advances in Agricultural and Food Biotechnology"

[9] S.Ranganna ,1986 "Handbook of Analysis and Quality Control for Fruit and Vegetable Product"

[10] T.Longvah and R.Ananthan, 2017 "Indian Food Composition Tables " National Institute of Nutrition

[11] Suasan Raatz “ Nutritive Values of Dry Beans"

[12] Tatjana kutos et al., 2002 "Dietary Fiber Content Of Dried and Processed Beans"

[13] Valdez and Maria "A Cookbook for Building a Solar Food Dryer".

*Corresponding author.

E-mail address: gsraghu2003@yahoo.co.in 